\title{
BUILDING ENERGY CODES POLICY OVERVIEW AND GOOD PRACTICES
}

Sadie Cox

National Renewable Energy Laboratory

Prepared for the U.S. Department of Energy and the

Australian Department of Industry, Innovation and Science

NREL/TP-6A20-65542

February 2016 


\section{BUILDING ENERGY CODES POLICY OVERVIEW AND GOOD PRACTICES}

Sadie Cox

National Renewable Energy Laboratory 


\section{NOTICE}

This manuscript has been authored by employees of the Alliance for Sustainable Energy, LLC ("Alliance") under Contract No. DE-AC36-08GO28308 with the U.S. Department of Energy ("DOE”).

This report was prepared as an account of work sponsored by an agency of the United States government. Neither the United States government nor any agency thereof, nor any of their employees, makes any warranty, express or implied, or assumes any legal liability or responsibility for the accuracy, completeness, or usefulness of any information, apparatus, product, or process disclosed, or represents that its use would not infringe privately owned rights. Reference herein to any specific commercial product, process, or service by trade name, trademark, manufacturer, or otherwise does not necessarily constitute or imply its endorsement, recommendation, or favoring by the United States government or any agency thereof. The views and opinions of authors expressed herein do not necessarily state or reflect those of the United States government or any agency thereof. 


\section{Acknowledgments}

The author would like to thank Ron Benioff, Victoria Healey, Terri Walters, Jaquelin Cochran, Jeffrey Logan, and David Mooney of the National Renewable Energy Laboratory, and Ian Lloyd and Jonah Steinbuck of the U.S. Department of Energy for their review and insights. All information and any omissions are the responsibility of the author, not the reviewers. 


\section{Table of Contents}

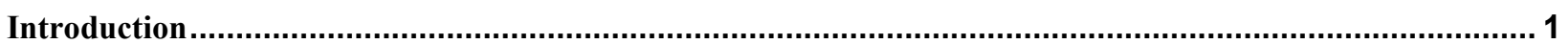

Policy Design and Good Practices.......................................................................................................4 4

Use model building codes to inform interlinked national and subnational building code efforts... 4

Engage stakeholders throughout the process to secure support for adoption and implementation.. 4

Conduct robust analysis to assess costs and benefits, inform code design, and provide a foundation for policy evaluation ...................................................................... 5

Develop a comprehensive and long term building code strategy, increasing in stringency over

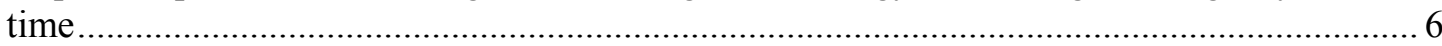

Build strong compliance infrastructure to ensure effective building code enforcement................ 7

Educate building sector stakeholders and code officials on the importance of building energy codes to increase support for compliance and recognize strong performance .....................8

Rigorously evaluate energy codes to understand strengths and weaknesses and support improved policy design and implementation over time....

Provide ongoing capacity building, training and resources to sector stakeholders to build support for code compliance and ensure effective design and implementation ................................ 9

Capture benefits of interlinked policies through designing a strong policy framework ............. 10

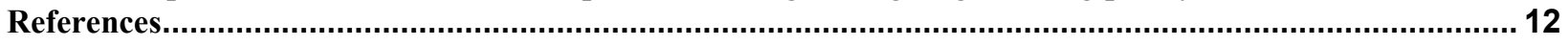

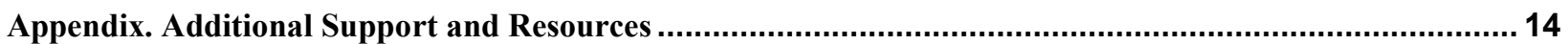




\section{List of Figures}

Figure 1. Building energy codes in place for new residential buildings .......................................... 2

Figure 2. Barriers to energy efficiency in the building sector ......................................................... 3

Figure 3. Percentage of potential energy savings of key energy efficiency measures across building

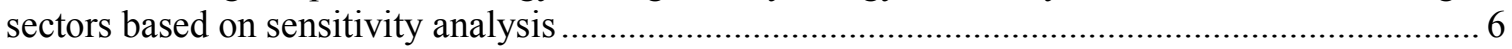

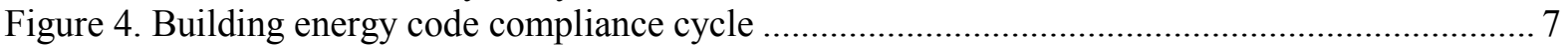

Figure 5. Example building sector clean energy policy package …................................................. 11

\section{List of Text Boxes}

Text Box 1. What is a Building Energy Code?

Text Box 2. Industry Stakeholder Engagement and Leadership Prompts Strong Support for Building Energy Codes

Text Box 3. Robust Analysis Supports Indonesia’s Building Energy Codes...................................... 6

Text Box 4. China's Multi-Tiered Approach Supports Building Energy Code Enforcement and Compliance 8

Text Box 5. Standard Bearers Award Recognizes and Rewards Innovative and Effective Building Code Action....

Text Box 6. Albania Supports Improvement of Implementation and Enforcement of Building Energy Codes

Text Box 7. Building Energy Codes Portal Supports Global Knowledge Sharing 


\section{Introduction}

Globally, $32 \%$ of total final energy consumption $^{1}$ is attributed to the building sector (IEA 2015). To support reduction of energy consumption in the building sector, energy codes set minimum energy efficiency standards for building technologies and design elements that may include: the building envelope; heating, ventilation, and air conditioning (HVAC) systems; lighting; and service water heating systems (Rosenberg et al. 2015). With effective implementation, building energy codes can support energy cost savings and complementary benefits associated with electricity reliability, air quality improvement, greenhouse gas emission reduction, increased comfort, and economic and social development. This policy brief seeks to support policymakers and implementers in designing effective building code programs.
Text Box 1. What is a Building Energy Code? Building energy codes are regulatory instruments that specify minimum energy efficiency standards for the residential and commercial building sectors. Building energy codes commonly mandate certain energy efficiency characteristics for building technologies. As another approach, outcome-based building energy codes are aligned with technology performance and provide target energy use levels for a building as a whole. Building codes can be mandatory or voluntary and are often complemented by other energy efficiency building incentives.

Building technologies and design elements that can be included in a building code are: the building envelope; heating, ventilation, and air conditioning (HVAC) systems; lighting; and service water heating systems.

Sources: IEA 2013; VanGeem and Colker 2014; EPA 2015; Rosenberg et al. 2015; IPEEC 2015; EERE 2013

As of 2015, approximately 40 national governments and many state and local jurisdictions around the world had building energy codes in place (IEA 2015; Clean Energy Solutions Center 2015; EPA 2015). Figure 1 presents countries that had energy codes in place for new residential buildings in 2015. Notably, a number of countries in Latin America, Africa, the Middle East, and Southeast Asia have not yet adopted energy codes for new residential buildings. Even fewer countries have adopted building energy codes for existing residential buildings. Similar geographic trends exist in the commercial sector.

\footnotetext{
1"Final energy consumption is the total energy consumed by end users, such as households, industry and agriculture. It is the energy which reaches the final consumer's door and excludes that which is used by the energy sector itself" (Eurostat 2012).
} 


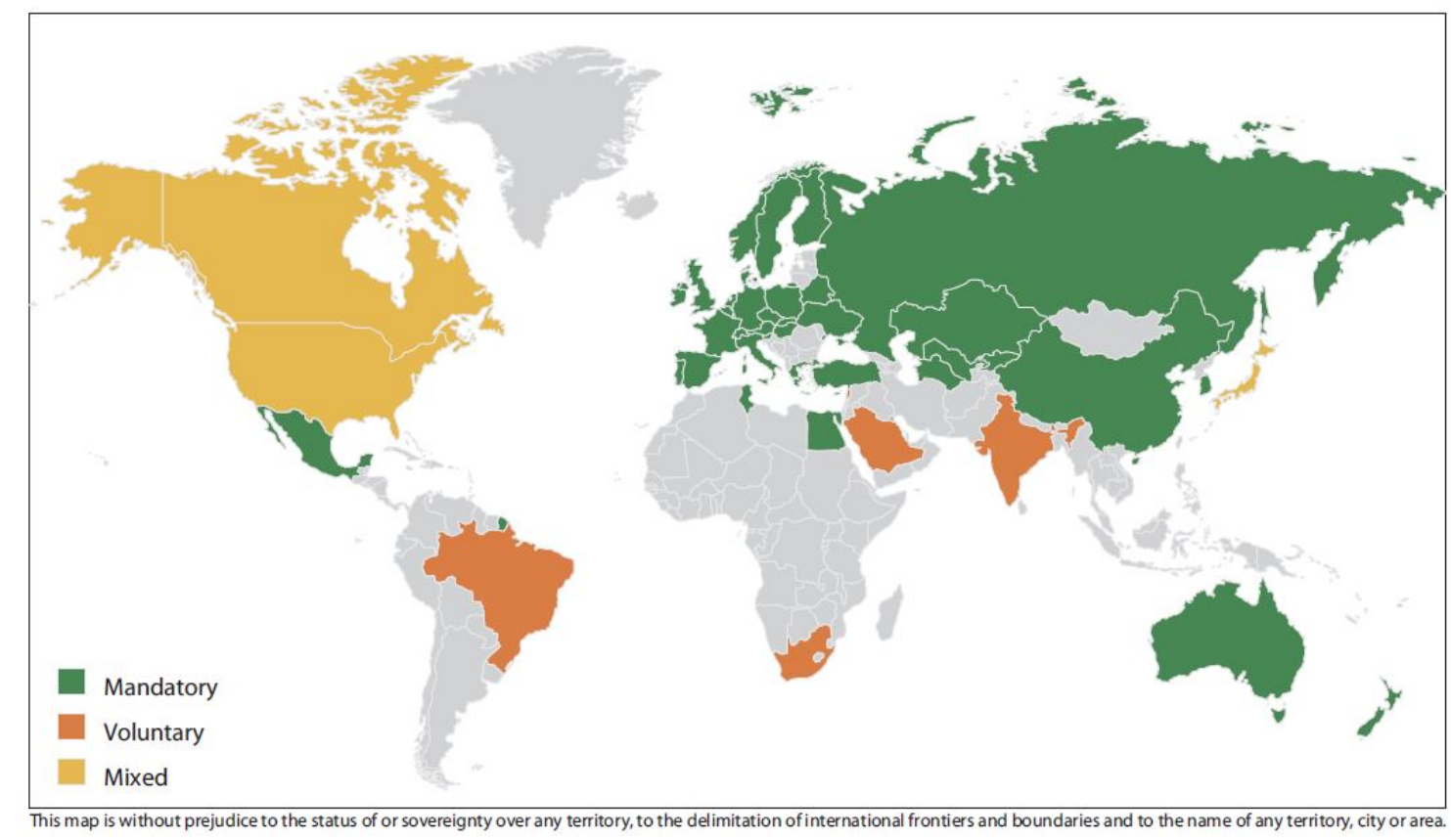

Figure 1. Building energy codes in place for new residential buildings

Source: IEA 2014

Building codes seek to address common barriers to energy efficient building design. In many markets, builders have little financial incentive to build energy efficient buildings because the subsequent owners or tenants will pay the energy bills and reap any benefits from lower costs. This is referred to as a "split incentive." In some cases, certain energy efficient technologies may result in increased initial capital costs for the builder, which take time to recover through energy cost savings. Further, homebuyers, with limited budgets, often opt for cosmetic or size-related home upgrades instead of energy efficiency, which hinders the uptake of energy efficiency technologies in residential buildings (EPA 2015). Figure 2 outlines these and other common barriers to energy efficiency in the building sector. 


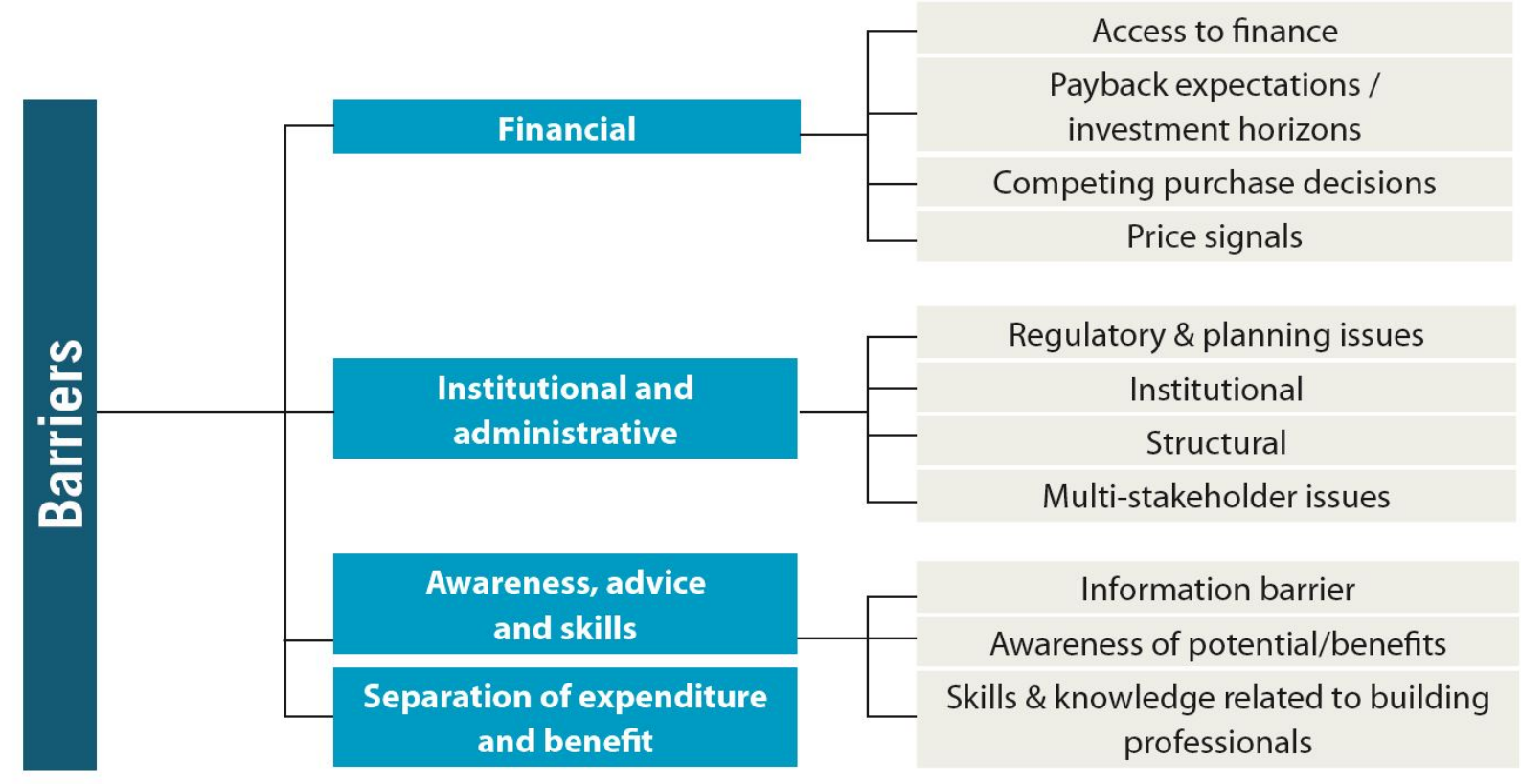

Figure 2. Barriers to energy efficiency in the building sector

Source: BPIE 2011

Robust building energy codes and implementation processes, coupled with other key policies and incentives, can address key barriers to deployment of energy-efficient technologies in the building sector (IEA 2013; EPA 2015). 


\section{Policy Design and Good Practices}

Key design elements and good practices, drawn from global experience and lessons, can support effective building code development and implementation, tailored to meet country-specific goals.

\section{Use model building codes to inform interlinked national and subnational building code efforts}

Model building energy codes developed by international institutions such as the International Code Council (ICC) can feed into national-level model codes often developed by Ministries of Energy with guidance, input, and support from technical institutions and other stakeholders. Model code development and revision at the national level often takes place over a multi-year period to ensure robust analysis and stakeholder input. Strong model codes developed at the national and/or international level can be used as a foundation for subnational codes tailored to local circumstances. Local authorities can also consider adoption of simplified codes developed by international institutions such as ICC or develop their own simplified codes that integrate easily understandable text and high-level tables summarizing key points. Local building codes are often adopted through regulatory mechanisms or legislation (EPA 2015; IEA 2014; IPEEC 2015).

\section{Engage stakeholders throughout the process to secure support for adoption and implementation}

Various stakeholders within the government, utilities, private sector, and technical institutions play key roles in ensuring effective design and implementation of building energy codes.

Governments provide the essential foundation for building code action. At the highest level, and as described above, national governments can support effective building code programs by developing model building energy codes that inform subnational efforts. In addition, energy efficiency and building energy code champions within the national government can play an important role in drawing attention to the benefits and critical nature of building code
Text Box 2. Industry Stakeholder Engagement and Leadership Prompts Strong Support for Building Energy Codes

The Texas Energy Code Compliance Collaborative (TECCC), which comprises industry stakeholders, provides an innovative approach to support local governments in implementation of building energy codes through training, education, and outreach campaigns. In partnership with the South-central Partnership for Energy Efficiency as a Resource (SPEER), TECCC works with local Energy Code Ambassadors to provide training on the ground based on local needs and challenges and to support peer to peer learning across municipalities. SPEER and the TECCC are funded by various public and private sources.

TECCC and SPEER are critical assets in supporting understanding and acceptance of building codes to facilitate effective implementation at the local level. Based on innovative engagement and education of private building sector leaders, Texas builders have come to strongly support code implementation and enforcement. For example, building sector leaders have noted their recognition of the critical need to penalize companies that produce low quality materials and buildings that can harm the industry as a whole.

Sources: Herbert 2015; EPA 2015 
implementation and enforcement (GBPN 2015; Clean Energy Solutions Center 2015). Subnational governments are at the front line of building code implementation and are crucial in tailoring codes to local circumstances, ensuring strong code enforcement, and catalyzing support at the local level.

Utilities can also support local building code implementation by including energy codes in integrated resource plans, contributing to analytical efforts to develop baselines and assess energy savings and other impacts, leading efforts to assess links with current energy efficiency programs, and supporting targeted outreach and education programs.

Engaging builders, owners, and other building industry actors involved with building management and development on the ground is also important to ensure support of code requirements and compliance preparedness (IEA 2014; EPA 2015; Levine et al. 2012). Text Box 2 presents successful efforts in Texas to engage building industry stakeholders with code implementation. In addition, technical institutions and non-governmental organizations focused on building sector energy analysis, outreach, and education often play key roles in supporting code development and implementation at the national and local levels.

Overall, creation of an inclusive stakeholder process that includes regular and ongoing engagement of the various actors described above can support provision of input and feedback on analysis and draft codes from key actors, early identification of potential challenges, and broader acceptance to support successful code adoption, implementation, and enforcement (EPA 2015; IEA 2014; Levine et al. 2012).

\section{Conduct robust analysis to assess costs and benefits, inform code design, and provide a foundation for policy evaluation}

As a first analytical step, it is important to develop a baseline that accurately reflects current building energy usage and other characteristics of the building market. Potential impacts of building energy codes can then be assessed in relation to this baseline. In particular, cost-benefit analysis can assess building energy and cost savings, greenhouse gas emission and other air pollution impacts, and impacts related to reliability of the power system, as well as construction and other administrative costs to implement the codes. Costs and benefits can then be presented to stakeholders and compared to inform development of the building codes. Identifying potential building code benefits in advance of adoption can broaden stakeholder support and provide a strong foundation for ongoing analysis of benefits. In addition to assessing costs and benefits, market analysis is also critical to ensure availability of products and suppliers to implement code requirements (EPA 2015). Finally, and very importantly, analysis of model codes and good practices in other countries and jurisdictions can also inform adaptation of effective codes to a specific area and context. Many high quality building codes have been developed globally, providing countries and jurisdictions with excellent models and resources to support new building code programs (Clean Energy Solutions Center 2015). Text Box 3 highlights Indonesia's analytical approach to support achievement of national level energy savings targets for new buildings (IBE 2011). 


\section{Text Box 3. Robust Analysis Supports Indonesia's Building Energy Codes}

To support design of building energy codes and achievement of building energy targets across sectors, the government of Indonesia assessed energy savings of various energy efficiency measures in Jakarta's building sector. As presented below, sensitivity analysis found that easily implementable measures could allow for energy savings of $30 \%-40 \%$ in new buildings in Jakarta. Implementing these measures through building codes may support Indonesia in meeting a high level target of $30 \%$ average energy savings in new buildings.

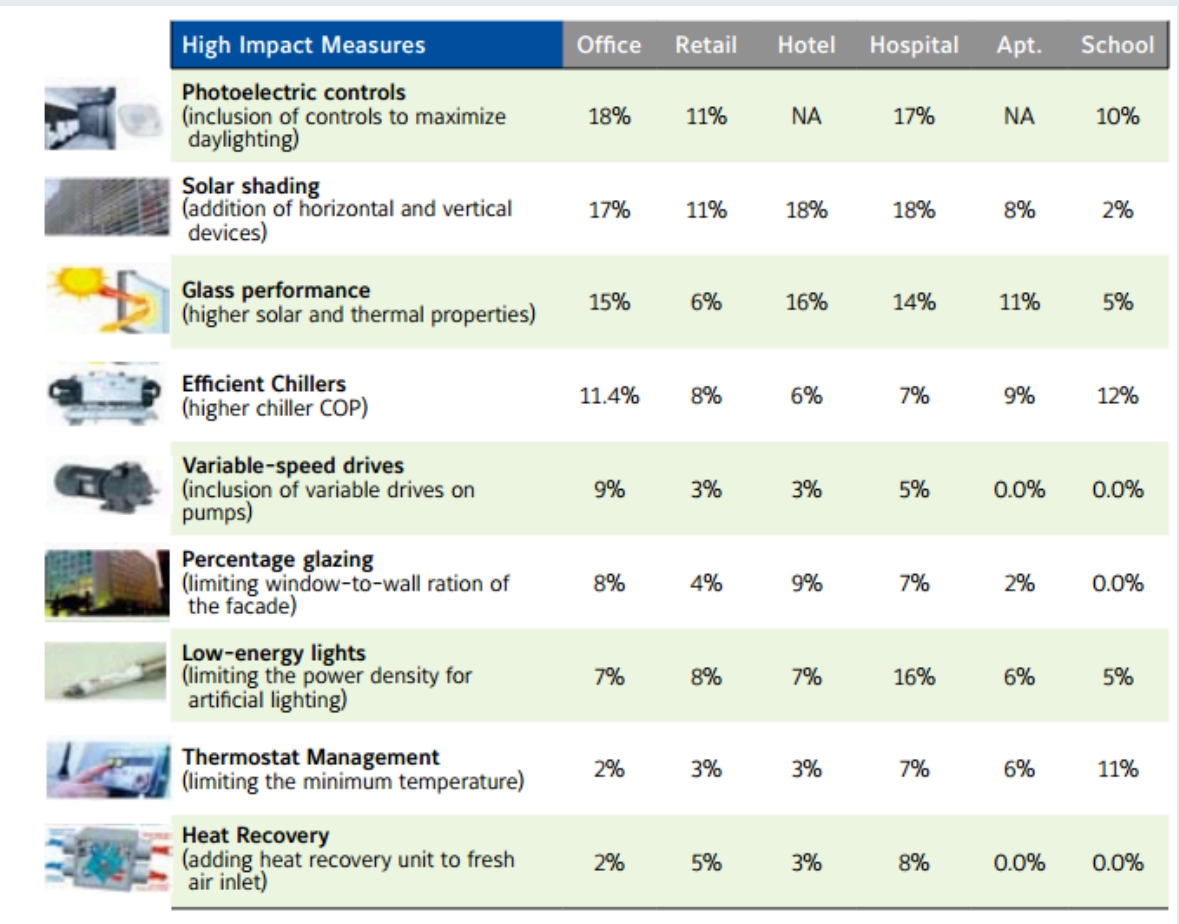

Source: Prashant Kapoor, IFC Green Building Strategy, World Bank Group, Washington D.C. (2011)

Figure 3. Percentage of potential energy savings of key energy efficiency measures across building sectors based on sensitivity analysis

\section{Develop a comprehensive and long term building code strategy, increasing in stringency over time}

Leveraging the analysis and stakeholder engagement described above, a plan of action can be developed to support building code implementation. Clearly articulated high level objectives and quantitative targets for the short, medium, and long term can provide framing for the strategy in relation to energy savings and other benefits such as air quality improvements. Effective targets often increase over time as building codes are more widely implemented and/or codes become more stringent. In some cases, countries may choose to first develop a plan for implementation in a single sector or for certain buildings (e.g., larger buildings) so they can test the code and learn from the experience. Countries may also begin by adopting building codes for new buildings because implementing energy efficiency technologies during construction of a building is often considerably less costly than retrofitting an existing inefficient building. However, while countries may begin with a more limited scope of building code implementation, it is important to have a longer term roadmap for implementation across the full building sector. As elaborated below, effective strategies 
encompass robust plans to implement, enforce, monitor, evaluate, and improve building codes over time (Rosenberg et al. 2015; IPEEC 2015).

\section{Build strong compliance infrastructure to ensure effective building code enforcement}

Compliance and enforcement of building energy codes is a key challenge, even in jurisdictions with advanced building code processes. Local governments are often the most critical actors in supporting effective compliance and building code enforcement (DOE 2015; EPA 2015; Levine et al. 2012; Clean Energy Solutions Center 2015). Based on global experience and as presented in Figure 4, the International Energy Agency put forth a compliance cycle that includes key inspections and other activities to support various stages of building code implementation and enforcement. Various approaches can be used to fund compliance. In many cases, builders may be required to cover compliance inspection costs through fees, while local and national governments may fund other enforcement activities, such as additional random periodic inspections.
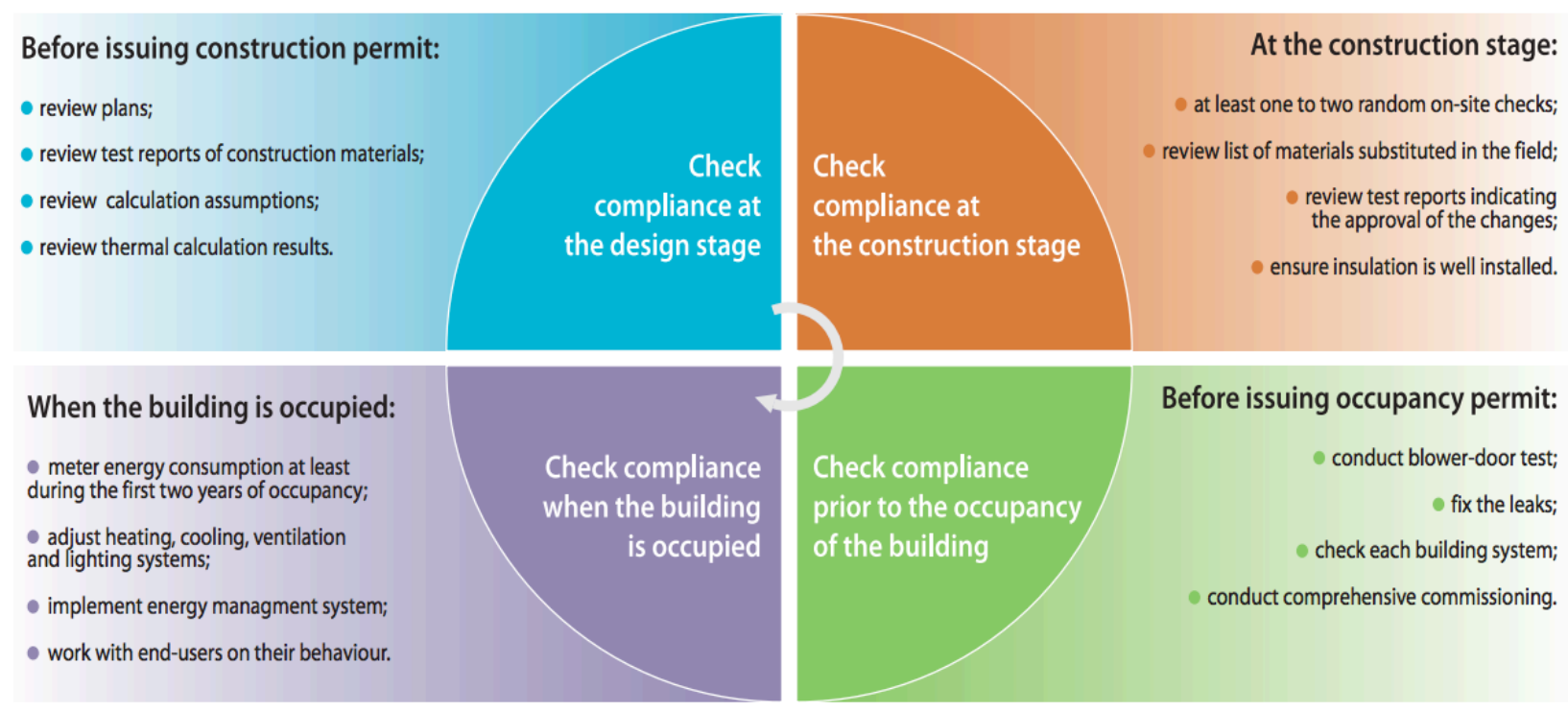

Figure 4. Building energy code compliance cycle

Source: IEA 2014

Accredited independent institutions are often designated to oversee compliance and inspections and ensure enforcement of building energy codes. Compliance data at the local level can feed into welldesigned and robust databases linked at the national level to support broader compliance analysis. In addition, the national government can put forth consistent methodologies for data analysis of local compliance that can support efficient compliance analysis at the national level. As described below, compliance analysis is critical in evaluating building code programs and to inform revisions and improvements. Openly communicating compliance trends to the public is also important and can allow public feedback to support improved processes in the future. For non-compliance, governments can consider fines, permit refusal, and other penalties (IEA 2014; Levine et al. 2012). Text Box 4 presents a brief case study on China's multi-tiered approach to support building code compliance. 
It is critical to have sufficient budget, staff, and analytical resources to support code implementation. At the local level, there is often a need to devote resources to training government staff and/or independent institutions to support compliance and enforcement. In addition, software tools and building material libraries are important to assess potential building material trade-offs and/or to perform whole building simulations. Various software tools are available to support compliance processes and can be chosen based on unique code features and local considerations (IEA 2014; EPA 2015; Levine et al. 2012).

\section{Educate building sector stakeholders and code officials on the importance of building energy codes to increase support for compliance and recognize strong performance}

Building energy code provisions are often viewed as less critical than other components of the building code (e.g., those related to structural integrity and safety), which presents one of the most significant barriers to building energy code enforcement and compliance. This
Text Box 4. China's Multi-Tiered Approach Supports Building Energy Code Enforcement and Compliance

Under the Code of Acceptance, China implemented a strong approach to enforce building energy codes that involves compliance checks during various stages of construction and engages multiple actors to support the process. Key stages and stakeholders are outlined below.

- Certified inspection companies, hired by developers, analyze building architectural plans to ensure compliance.

- Local quality supervision agency reviews compliance report from the inspection company.

- Local construction administration agency provides a building license following positive compliance report review.

- Certified engineering inspection companies, hired by the developer, perform building inspections throughout the construction process.

- Local quality supervision agency also performs compliance checks during the building process.

- Building projects may also be inspected through random annual inspections conducted through the Ministry of Housing. If a building fails the inspection, the issues can be corrected within 30 days or the developer is fined.

- If buildings pass all compliance checks described above, the local construction agency issues occupancy permits.

Source: IEA 2014 key challenge often leads to inadequate allocation of resources and time for building code enforcement. To address this issue, policymakers, in partnership with industry leaders, can design targeted education and outreach programs for various building sector stakeholders and code officials to communicate the critical nature and benefits of building energy efficiency (e.g., energy savings, electricity system reliability, improved indoor air quality). In addition, and as presented above, highlevel champions within the public and private sectors can be instrumental in supporting such outreach campaigns and creating a cultural shift to support building energy efficiency. Recognition programs can also be put in place to incentivize and build support for compliance. These programs can reward code officials and builders actively engaged in effective code compliance and enforcement (DOE 2015; Solutions Center 2015). Text Box 5 describes an innovative award program to incentivize effective building code implementation through dedicated action. 


\section{Rigorously evaluate energy codes to understand strengths and weaknesses and support improved policy design and implementation over time}

Building on compliance data, policymakers at the local and national level can assess the effectiveness of building energy codes to support future improvements. In addition to overall compliance levels, policymakers may be interested in assessing energy savings, grid reliability improvements, emission reductions, and other development benefits such as job creation. Outputs of the analysis can be compared with targets and goals, as well as pre-implementation studies, to evaluate effectiveness and inform potential code revisions and improvements based on successes and challenges. In addition, through interviews, surveys, or independent Text Box 5. Standard Bearers Award Recognizes and Rewards Innovative and Effective Building Code Action

The U.S. Standard Bearers Award provides national recognition to building code stakeholders supporting building energy code compliance through innovative and dedicated action. The award is open to governments and private sector leaders improving building energy code compliance. The award inherently recognizes that many building code implementers are working with constrained budgets and in institutions that may not be fully supportive of building code action. Presenting and recognizing innovative work across building sector peers can encourage replication and build motivation for improved action.

evaluations, implementers can assess stakeholder engagement processes as well as training and other technical assistance services provided to support code development and implementation. Commonly, jurisdictions will update codes every three to five years or following a national-level model code update. Following code updates, adequate time and resources should be allocated to train key building stakeholders, described above, on implementation of the new codes and to allow manufacturers and industry to supply any new technologies or products required to meet codes (IEA 2014; EPA 2015; IPEEC 2015).

Compliance data and surveys can also shed light on the state of the building market more broadly to inform code improvements. For example, the building market may naturally adopt technologies above code that could be considered for inclusion in future code revisions (EPA 2015).

\section{Provide ongoing capacity building, training and resources to sector stakeholders to build support for code compliance and ensure effective design and implementation}

Ongoing targeted training and capacity building are crucial elements in supporting successful implementation of building energy codes. Training and other educational efforts can build the capacity of policymakers and technical staff to analyze, design, implement, monitor, and evaluate codes. In addition, training local building designers, builders, suppliers, and technology installers is often crucial to ensure effective code implementation. In particular, training private sector actors to model building energy use is an area of need in many contexts. As noted above, educating building owners and the public more broadly on energy efficiency and building codes can also build support for code compliance. Training should continue after the code is initially implemented to ensure building market actors are regularly educated on new technologies, design elements, and/or potential revisions to the code. In addition, local implementers, within government and the private sector, can be provided with resources that clearly articulate the codes, building energy science information and tools, inspection guidelines, and key contacts within the government, technical institutes, and the private sector that can provide technical assistance and support. Text Box 6 presents Albania's efforts 
to support building code development and implementation, highlighting education as a key component and development of a knowledge guide for residential retrofits. Adequate time and budget in addition to dedicated training staff are critical in supporting effective capacity building efforts (EPA 2015; IPEEC 2015).

\section{Capture benefits of interlinked policies through designing a strong policy framework}

Building energy codes can be largely synergistic with other policies and programs. At the highest level, building energy codes can be integrated with broader national and local energy, energy efficiency, and climate strategies, as well as integrated resource plans prepared by utilities. These higher level strategies can provide broader framing and objectives to contextualize action on building codes and broaden support for building energy codes across the government. Building energy codes can also be synergistic with regulatory policies such as greenhouse gas emission regulations and may be integrated as key actions to meet regulations. As other key examples, building energy codes can be linked with building efficiency financial incentive programs and voluntary building energy performance certification programs, such as the U.S. Green Building Council's Leadership in Energy and Environmental Design (LEED) program and Australia's National Australian Built Environment Rating System (NABERS). ${ }^{2}$ Financial mechanisms and recognition programs can provide a strong incentive for builders to go above and beyond the minimum energy efficiency requirements adopted in building codes. Voluntary building performance programs can also provide a mechanism to test potential technologies to be included in future codes and, in some cases, reduce administrative burden by allowing independently certified buildings to automatically comply with codes. Finally, holistic clean energy programs often link on-site renewable energy incentives and programs with building energy efficiency efforts. As presented in Figure 5, policymakers can integrate building energy codes under broader building sector clean energy strategies and policy packages to ensure opportunities and synergies are captured (EPA 2015; BPIE 2011).

\footnotetext{
${ }^{2}$ LEED is a "green building certification program that recognizes best-in-class building strategies and practices. To receive LEED certification, building projects satisfy prerequisites and earn points to achieve different levels of certification. Prerequisites and credits differ for each rating system, and teams choose the best fit for their project" (USGBC 2015). NABERS is "a national rating system that measures the environmental performance of Australian buildings, tenancies and homes" (Australia Office of Environment and Heritage 2016).
} 


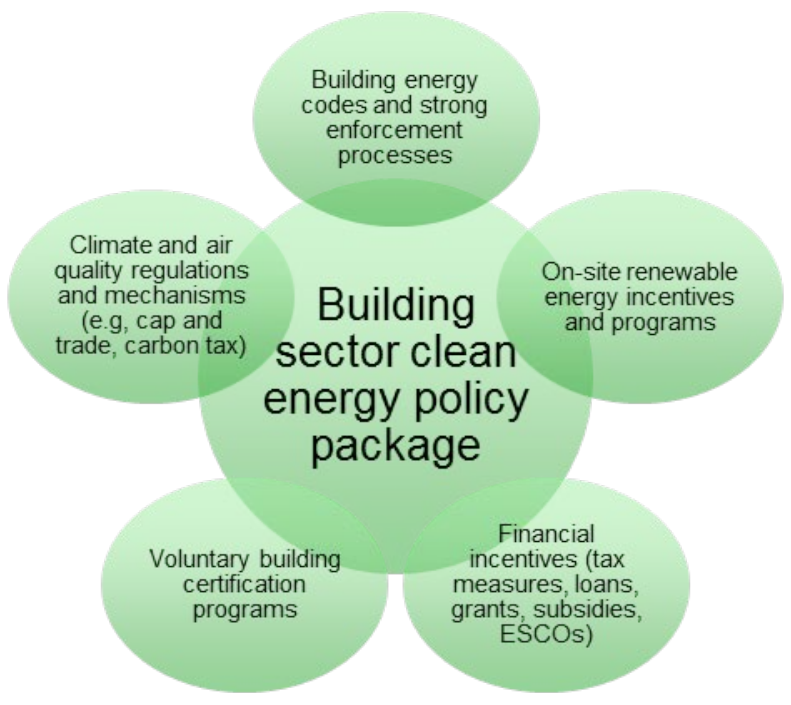

Figure 5. Example building sector clean energy policy package

By scaling up deployment of energy efficiency technologies, building energy codes can support significant energy cost savings, improved grid reliability, air quality improvements, and greenhouse gas emission reductions. Global lessons and good practices from around the world can facilitate design and implementation of both new and improved building energy codes. While much progress has been made, there are still significant opportunities for collaboration and innovation in this space to support accelerated progress towards a collective clean energy future.

\section{Text Box 7. Building Energy Codes Portal Supports Global Knowledge Sharing}

The Building Energy Codes Portal was developed to support peer learning and knowledge sharing among stakeholders engaged with building code design and implementation globally. Through collaborative input from the founding organizations-International Partnership for Energy Efficiency Cooperation (IPEEC), Global Buildings Performance Network (GBPN), and Pacific Northwest National Laboratory (PNNL) - the web portal provides information on:

- Effective codes implemented around the world including scope and stages of development

- Enforcement mechanisms to support successful outcomes

- Tools and training resources to support code design and implementation, including testing and rating building materials to ensure compliance

In addition, the web portal will integrate further peer learning features and best practice materials in the future. 


\section{References}

Australia Office of Environment and Heritage. 2016. "NABERS: National Australian Built Environment Rating System.” Accessed January.

http://www.nabers.gov.au/public/WebPages/Home.aspx.

BPIE (Buildings Performance Institute Europe). 2011. Europe's Buildings Under the Microscope: A Country-by-Country Review of the Energy Performance of Buildings. Milwaukee: Johnson Controls.

http://www.institutebe.com/InstituteBE/media/Library/Resources/Existing\%20Building\%20Retrofits/Eur opes-Buildings-Under-the-Microscope-BPIE.pdf.

Clean Energy Solutions Center. 2015. "Guiding Residential Energy Efficiency Retrofits in Albania." Accessed November. https://cleanenergysolutions.org/expert/impacts/albaniaefficiency-retrofits.

DOE (U.S. Department of Energy). 2015. Achieving Energy Savings and Emission Reductions from Building Energy Codes: A Primer for State Planning Washington, D.C.: U.S. Department of Energy.

https://www.energycodes.gov/sites/default/files/documents/Codes_Energy_Savings_State_Prime r.pdf.

EERE (U.S. Department of Energy Office of Energy Efficiency and Renewable Energy). 2013. "Building Energy Codes Program: Toolkit Definitions." Last modified January 31. https://www.energycodes.gov/resource-center/ace/definitions.

EPA (Environmental Protection Agency). 2015. Energy and Environment Guide to Action: State Policies and Best Practices for Advancing Energy Efficiency, Renewable Energy, and Combined Heat and Power. 2015 edition. Washington, D.C.: United States Environmental Protection Agency. http://www3.epa.gov/statelocalclimate/documents/pdf/guide action_full.pdf.

Eurostat. 2012. "Glossary: Final Energy Consumption." Last modified September 7. http://ec.europa.eu/eurostat/statistics-explained/index.php/Glossary:Final energy consumption.

GBPN (Global Buildings Performance Network). 2015. "Building Energy Codes Portal." Accessed November. http://www.gbpn.org/beet-3/.

Herbert, Christine. 2015. Texas Energy Code Compliance Collaborative: 2014 Energy Code Adoption Report. Austin, TX: The South-central Partnership for Energy Efficiency as a Resource. https://eepartnership.org/wp-content/uploads/2015/07/teccc-2014-energy-codeadoption-report.pdf.

IBE (Institute for Building Efficiency). 2011. "Driving Transformation to Energy Efficient Buildings: Policies and Actions - Building Efficiency Codes and Standards." Milwaukee: Johnson Controls.

http://www.institutebe.com/InstituteBE/media/Library/Resources/Energy $\% 20$ and $\% 20$ Climate $\% 2$ $\underline{\text { PPolicy/Driving-Transformation-to-EE-Buildings-Policies-Actions-Codes-Standards.pdf. }}$ 
IEA (International Energy Agency). 2015. "FAQ: Energy Efficiency." Accessed November. https://www.iea.org/aboutus/faqs/energyefficiency/.

IEA (International Energy Agency). 2013. Modernising Building Energy Codes to Secure Our Global Energy Future. Paris: International Energy Agency. https://www.iea.org/publications/freepublications/publication/ PolicyPathwaysModernisingBuildingEnergyCodes.pdf.

IMT (Institute for Market Transformation). 2015. "IMT and ICC Present the 2015 Standard Bearers Awards." Accessed November. http://www.imt.org/codes/code-compliance/standardbearers.

IPEEC (International Partnership for Energy Efficiency Cooperation). 2015. Delivering Energy Savings in Buildings. Paris: OECD/IPEEC.

http://www.ipeec.org/publications/download/id/1962.html.

Levine, Mark, Stephane de la Rue de Can, Nina Zheng, Christopher Williams, Jennifer Amann, Dan Staniaszek. 2012. Building Energy Efficiency: Best Practice Policies and Policy Packages. Berkeley, CA: Lawrence Berkeley National Laboratory, prepared for Global Buildings Performance Network. http://www.gbpn.org/reports/building-energy-efficiency-best-practicepolicies-and-policy-packages.

Rosenberg, M., J. Zhang, R. Hart, and R. Athalye. 2015. Roadmap for the Future of Commercial Energy Codes. Richland, WA: Pacific Northwest National Laboratory. http://www.pnnl.gov/main/publications/external/technical_reports/PNNL-24009.pdf.

USGBC (U.S. Green Building Council). 2015. “LEED.” Accessed November. http://www.usgbc.org/leed.

VanGeem, Martha, and Ryan M. Colker. 2014. "Energy Codes and Standards.” Whole Building Design Guide. Last updated March 24. https://www.wbdg.org/resources/energycodes.php. 


\section{Appendix. Additional Support and Resources}

Targeted technical assistance regarding the design and implementation of renewable energy policies is provided by:

- Clean Energy Solutions Center Ask an Expert-The Solutions Center Ask an Expert service is available at no cost to government agency representatives from any country and the technical institutes assisting them. If your request qualifies for assistance, you will be matched with the Solutions Center expert who is most qualified to help you, for up to 40 hours of assistance. For more information, see cleanenergysolutions.org/expert.

- Climate Technology Center \& Network (CTCN) - Climate Technology Center \& Network (CTCN) - The CTCN provides technical assistance in response to requests submitted by developing countries via their National Designated Entities (NDEs). Upon receipt of such requests, the CTC quickly mobilizes its global Network of climate technology experts to design and deliver a customized solution tailored to local needs. The CTCN does not provide funding directly to countries, but instead supports the provision of technical assistance provided by experts on specific climate technology sectors. For more information, see ctcn.org/technical-assistance.

Additional resources - including good practice resources and publications, policy examples and databases, webinars and training resources, and a glossary - are available at cleanenergysolutions.org/policy-briefs/building-codes/resources. 